\title{
Material deprivation and leading causes of death by gender: evidence from a nationwide small area study
}

\author{
J Benach, Y Yasui, C Borrell, M Sáez, M I Pasarin
}

\begin{abstract}
Study objective-To investigate the association between material deprivation and $\mathbf{1 0}$ leading causes of death by gender.

Design-Small area cross sectional ecological study using two dimensions of material deprivation (Index 1 and Index 2) drawn from 1991 census and cause specific mortality data aggregated for 1987-1995. Setting-2218 small areas in Spain.

Main results-Strong detrimental associations of two deprivation indices were found with top six leading causes of death for men and top seven leading causes of death for women, except breast cancer. For men, the highest percentages of excess mortality (between $40 \%$ and $60 \%$ ) were found for smoking and alcohol related causes of death such as lung cancer, chronic obstructive pulmonary diseases, and cirrhosis while for women the highest percentages of excess mortality (between $40 \%$ and $60 \%$ ) were found for diet related causes such as diabetes and ischaemic heart disease.

Conclusions-Health inequality is a widespread phenomenon in the majority of the top leading causes of deaths of the nation. Increasing levels of deprivation indices are associated with mortality risk differently by both cause and gender. Results suggest that deprivation effects mainly captured by Index 2 may manifest largely as unfavourable health behaviours leading to gender specific sets of causes of deaths. Findings of this study are consistent with the idea that material deprivation determines health inequality through both an increase of general susceptibility to ill health, leading to excess mortality in a wide range of causes, and a set of specific factors, resulting in an increased risk of death from a specific set of causes in each gender.

(F Epidemiol Community Health 2001;55:239-245)
\end{abstract}

Progressive increase of mortality risk by the degree of material deprivation at ecological (area) levels has been found in various European countries. Strong positive associations have been documented in England and Wales, ${ }^{1-3}$ Scotland, ${ }^{2}{ }^{4}$ the Netherlands, ${ }^{6}$ Sweden $^{7}$ and Spain. ${ }^{8}{ }^{9}$

Given the consistent findings on the deprivation-mortality link and their large implications on public health, ${ }^{12} 1011$ the detrimental influence of material deprivation must be elucidated for specific causes of death.

Social differentials in mortality seem to apply to most of the main causes of death. ${ }^{12}$
Unfortunately, however, studies of cause specific mortality according to the levels of deprivation have been relatively limited. ${ }^{11}{ }^{13-15}$ Few area-based studies have investigated entire nations for long periods of time: rather large units of regions or short periods of time have been analysed. Additionally, individual-based studies are inevitably restrictive with respect to both the target population and the number of specific causes of death being analysed. The largest study has been a comparative study of middle aged men in 11 European countries. ${ }^{16}$ This study showed that the influence of social class on overall mortality in men was similar across countries but varied appreciably by cause. These authors pointed to the pressing need for nationwide population-based studies from each country to further extend our understanding of inequalities in health beyond overall mortality. More recently, a study analysed differences in total mortality and some causes of death by educational level among men and women in seven countries. ${ }^{17}$ The authors concluded the need to explore the interaction between socioeconomic factors, sex and mortality to provide clues to the explanation of inequalities in health.

In this article, we report a nationwide population-based study of cause specific mortality by gender in relation to material deprivation. We studied the top 10 leading causes of death for each gender in 2218 small areas of Spain for a nine year period according to the levels of material deprivation.

\section{Methods}

Using municipalities as the building blocks, and applying a Geographical Information System, 2220 small areas (hereafter referred to as "zones") with at least 3500 inhabitants were constructed in previous studies. ${ }^{18}{ }^{19}$ In this investigation, the number of zones was reduced by two because of the lack of data in the two Spanish northern African cities of Ceuta and Melilla. Cause specific mortality data aggregated for 1987-95 were obtained from death certificates of the National Institute of Statistics of Spain by age and gender in each of the 2218 zones. From the cause specific mortality data, 10 leading causes of death in Spain in the study period were calculated for men and women separately. Causes of death were grouped according to the grouping scheme used by the Spanish Epidemiological Mortality Surveillance Unit, the National Centre of Reference of the Spanish Ministry of Health, which basically follows the ICD-9 standard list with 50 groups of causes of death. ${ }^{20}$ In Spain the completion and 
Table 1 Number and proportion of deaths of 10 leading causes of death (1987-1995) for each gender

\begin{tabular}{lrr}
\hline Causes of death (ICD-9) & Number & $\%$ \\
\hline Men & & \\
Ischaemic heart disease (410-414) & 178107 & 11.4 \\
Cerebrovascular disease (430-438) & 157769 & 10.1 \\
All other heart diseases (415-429) & 141672 & 9.0 \\
Lung cancer (162) & 118025 & 7.5 \\
Chronic obstructive pulmonary diseases (COPD) (490-496) & 91920 & 5.9 \\
Cirrhosis (571) & 47384 & 3.0 \\
Traffic accidents (E 810-829) & 46352 & 3.0 \\
Prostate cancer (185) & 40610 & 2.6 \\
Stomach cancer (151) & 36576 & 2.3 \\
Acute respiratory infections, pneumonia and influenza (ARI) & & \\
$\quad$ (460-466,480-487) & 34885 & 2.2 \\
All causes of death (000-999) & 1568186 & 100 \\
& & \\
Women & & 16.2 \\
Cerebrovascular disease (430-438) & 225758 & 14.8 \\
All other heart diseases (415-429) & 206138 & 9.3 \\
Ischaemic heart disease (410-414) & 129363 & 3.7 \\
Diabetes (250) & 51896 & 3.7 \\
Atherosclerosis (440) & 50352 & 3.6 \\
Breast cancer (174) & 49412 & 2.7 \\
Chronic obstructive pulmonary diseases (COPD) (490-496) & 36876 & 2.6 \\
Dementia, Alzheimer (290.0.1,331.0.2.8.9) & 36558 & 2.5 \\
Acute respiratory infections, pneumonia and influenza (ARI) & & 1.9 \\
$\quad$ (460-466,480-487) & 34681 & 100 \\
Colon cancer (153) & 26641 & \\
All causes of death (000-999) & 1389913 & \\
\hline & & \\
\hline
\end{tabular}

coding of death certificates follows the WHO recommendations. Studies have shown that quality of mortality statistics in Spain is comparable to other European Countries. ${ }^{21}$ Table 1 presents ICD-9 codes and proportion of overall mortality of 10 leading causes of death for each gender. Population data in the 1991 Spanish Census by age, gender, and zone provided denominators for computing mortality rates. To describe age adjusted relative risk of mortality, we computed standardised mortality ratios (SMRs) for the 10 leading causes of death for each zone using all ages. ${ }^{22}$

Four area-based indicators of material deprivation, (namely, unemployment, illiteracy, social class and overcrowding), were drawn from the
1991 Spanish census for each zone. The census is the single source of reliable and comparable socioeconomic data with a complete coverage of Spain's population at the small area level. The four census-based indicators of this study were selected as the best indicators available in the 1991 Spanish census-based on the theoretical criteria described previously. ${ }^{9}$ Two summary indices of deprivation (referred to as Index 1 and Index 2) were derived using the principal component analysis method. This method allowed for reduction of redundancy in the four indicators producing two uncorrelated indices with reasonable levels of societal interpretation. Basically, Index 1 captured a deprivation dimension measured by unemployment, illiteracy and low social class, while Index 2 represented a deprivation dimension measured by overcrowding with a small component of unemployment and illiteracy. Methodological details for the derivation of the two indices are given elsewhere. ${ }^{9}$ Deprivation scores for both indices were given for each zone by factor scores. Increasing scores in each index indicate greater levels of deprivation. The scores were then categorised into quintiles and tertiles.

The association between deprivation and cause specific mortality was explored descriptively for each gender by comparing the cause specific SMR across quintiles of each deprivation index. This descriptive analysis examined the gradient of Index 1 and Index 2 effects separately without considering the possibility of their interaction effects. We then assessed the pattern and gradient of deprivation effects by using a Poisson regression model for cause specific mortality rates. The SMRs were computed using the age specific mortality rates of total Spain as the reference rates. The number of excess deaths were computed based on the regression model by hypothetically

Table 2 Ten leading cause specific SMRs by deprivation indices (quintiles) for men

\begin{tabular}{|c|c|c|c|c|c|c|c|c|c|c|}
\hline \multirow[b]{2}{*}{ Men } & \multicolumn{5}{|l|}{ Index 1} & \multicolumn{5}{|l|}{ Index 2} \\
\hline & $\begin{array}{l}\text { Least } \\
\text { deprived }\end{array}$ & Second & Third & Fourth & $\begin{array}{l}\text { Most } \\
\text { deprived }\end{array}$ & $\begin{array}{l}\text { Least } \\
\text { deprived }\end{array}$ & Second & Third & Fourth & $\begin{array}{l}\text { Most } \\
\text { deprived }\end{array}$ \\
\hline Ischaemic heart disease & 94 & 94 & 94 & 99 & 101 & 88 & 88 & 95 & 96 & 114 \\
\hline Cerebrovascular disease & 89 & 97 & 104 & 117 & 121 & 101 & 101 & 103 & 106 & 117 \\
\hline All other heart diseases & 106 & 99 & 105 & 101 & 111 & 95 & 101 & 104 & 106 & 116 \\
\hline Lung cancer & 80 & 86 & 91 & 94 & 99 & 78 & 78 & 90 & 97 & 108 \\
\hline COPD & 88 & 90 & 100 & 111 & 115 & 90 & 95 & 104 & 106 & 108 \\
\hline Cirrhosis & 72 & 81 & 91 & 92 & 91 & 73 & 78 & 87 & 87 & 102 \\
\hline Traffic accidents & 118 & 123 & 115 & 117 & 87 & 115 & 115 & 114 & 118 & 99 \\
\hline Prostate cancer & 101 & 102 & 103 & 99 & 87 & 100 & 96 & 98 & 100 & 98 \\
\hline Stomach cancer & 103 & 104 & 108 & 101 & 89 & 102 & 106 & 102 & 99 & 96 \\
\hline ARI & 86 & 88 & 92 & 94 & 97 & 88 & 87 & 91 & 91 & 100 \\
\hline
\end{tabular}

Table 3 Ten leading cause specific SMRs by deprivation indices (quintiles) for women

\begin{tabular}{|c|c|c|c|c|c|c|c|c|c|c|}
\hline \multirow[b]{2}{*}{ Women } & \multicolumn{5}{|l|}{ Index 1} & \multicolumn{5}{|l|}{ Index 2} \\
\hline & $\begin{array}{l}\text { Least } \\
\text { deprived }\end{array}$ & Second & Third & Fourth & $\begin{array}{l}\text { Most } \\
\text { deprived }\end{array}$ & $\begin{array}{l}\text { Least } \\
\text { deprived }\end{array}$ & Second & Third & Fourth & $\begin{array}{l}\text { Most } \\
\text { deprived }\end{array}$ \\
\hline Cerebrovascular disease & 92 & 99 & 106 & 125 & 133 & 108 & 108 & 111 & 110 & 119 \\
\hline All other heart diseases & 108 & 105 & 107 & 111 & 125 & 106 & 108 & 111 & 111 & 121 \\
\hline Ischaemic heart disease & 89 & 93 & 99 & 105 & 114 & 92 & 91 & 98 & 98 & 120 \\
\hline Diabetes & 84 & 91 & 101 & 120 & 123 & 93 & 95 & 102 & 99 & 130 \\
\hline Atherosclerosis & 91 & 100 & 102 & 106 & 80 & 97 & 89 & 102 & 100 & 91 \\
\hline Breast cancer & 91 & 94 & 97 & 91 & 76 & 91 & 85 & 92 & 89 & 91 \\
\hline COPD & 100 & 99 & 101 & 113 & 110 & 100 & 105 & 104 & 112 & 101 \\
\hline Dementia, Alzheimer & 88 & 98 & 100 & 89 & 67 & 94 & 89 & 95 & 89 & 74 \\
\hline ARI & 92 & 97 & 94 & 100 & 108 & 98 & 96 & 97 & 95 & 104 \\
\hline Colon cancer & 95 & 96 & 94 & 96 & 86 & 95 & 93 & 94 & 93 & 91 \\
\hline
\end{tabular}


Table 4 Relative mortality risk (and 95\% CI) by two indices of deprivation (Index 1, Index 2) and tertiles (low, medium, high) for top 10 leading causes of death among men

\begin{tabular}{|c|c|c|c|}
\hline \multirow[b]{2}{*}{ Ischaemic heart disease } & \multicolumn{3}{|l|}{ Index 2} \\
\hline & Low & Medium & High \\
\hline \multicolumn{4}{|l|}{ Index 1} \\
\hline Low & 1.00 & $1.17(1.03,1.34)$ & $1.28(1.10,1.50)$ \\
\hline Medium & $1.07(0.94,1.22)$ & $1.16(1.02,1.33)$ & $1.29(1.13,1.48)$ \\
\hline \multirow[t]{2}{*}{ High } & $1.11(0.97,1.26)$ & $1.19(1.04,1.35)$ & $1.32(1.16,1.50)$ \\
\hline & \multicolumn{3}{|l|}{ Index 2} \\
\hline Cerebrovascular disease & Low & Medium & High \\
\hline \multicolumn{4}{|l|}{ Index 1} \\
\hline Low & 1.00 & $1.09(1.00,1.18)$ & $1.08(0.95,1.23)$ \\
\hline Medium & $1.17(1.11,1.23)$ & $1.16(1.09,1.22)$ & $1.27(1.20,1.33)$ \\
\hline \multirow[t]{2}{*}{ High } & $1.35(1.29,1.42)$ & $1.39(1.33,1.47)$ & $1.42(1.35,1.50)$ \\
\hline & \multicolumn{3}{|l|}{ Index 2} \\
\hline All other heart diseases & Low & Medium & High \\
\hline \multicolumn{4}{|l|}{ Index 1} \\
\hline Low & 1.00 & $1.07(0.99,1.16)$ & $1.19(1.06,1.34)$ \\
\hline Medium & $1.05(0.98,1.12)$ & $1.10(1.00,1.21)$ & $1.11(1.02,1.21)$ \\
\hline \multirow[t]{2}{*}{ High } & $1.07(0.99,1.15)$ & $1.13(1.05,1.22)$ & $1.22(1.13,1.32)$ \\
\hline & \multicolumn{3}{|l|}{ Index 2} \\
\hline Lung cancer & Low & Medium & High \\
\hline \multicolumn{4}{|l|}{ Index 1} \\
\hline Low & 1.00 & $1.29(1.05,1.57)$ & $1.46(1.19,1.78)$ \\
\hline Medium & $1.10(0.90,1.33)$ & $1.39(1.13,1.70)$ & $1.58(1.30,1.92)$ \\
\hline \multirow[t]{2}{*}{ High } & $1.08(0.89,1.31)$ & $1.25(1.03,1.52)$ & $1.58(1.30,1.92)$ \\
\hline & \multicolumn{3}{|l|}{ Index 2} \\
\hline$C O P D^{\star}$ & Low & Medium & High \\
\hline \multicolumn{4}{|l|}{ Index 1} \\
\hline Low & 1.00 & $1.28(1.15,1.43)$ & $1.27(1.01,1.58)$ \\
\hline Medium & $1.28(1.15,1.42)$ & $1.57(1.40,1.77)$ & $1.70(1.47,1.95)$ \\
\hline \multirow[t]{2}{*}{ High } & $1.49(1.34,1.66)$ & $1.59(1.42,1.77)$ & $1.59(1.43,1.76)$ \\
\hline & \multicolumn{3}{|l|}{ Index 2} \\
\hline Cirrhosis & Low & Medium & High \\
\hline Index 1 & & & \\
\hline Low & 1.00 & $1.26(1.02,1.56)$ & $1.51(1.28,1.79)$ \\
\hline Medium & $1.11(0.94,1.31)$ & $1.44(1.22,1.70)$ & $1.60(1.34,1.92)$ \\
\hline High & $1.11(0.93,1.31)$ & $1.34(1.14,1.58)$ & $1.48(1.26,1.75)$ \\
\hline & Index 2 & & \\
\hline Traffic accidents & Low & Medium & High \\
\hline Index 1 & & & \\
\hline Low & 1.00 & $0.99(0.86,1.14)$ & $0.78(0.65,0.95)$ \\
\hline Medium & $1.09(0.96,1.25)$ & $1.01(0.88,1.16)$ & $0.85(0.75,0.98)$ \\
\hline High & $0.95(0.83,1.08)$ & $0.96(0.84,1.10)$ & $0.88(0.77,1.00)$ \\
\hline & Index 2 & & \\
\hline Prostate cancer & Low & Medium & High \\
\hline Index 1 & & & \\
\hline Low & 1.00 & $1.03(0.96,1.10)$ & $1.05(0.97,1.13)$ \\
\hline Medium & $1.03(0.96,1.11)$ & $1.01(0.94,1.08)$ & $1.01(0.94,1.09)$ \\
\hline High & $0.93(0.86,1.01)$ & $0.90(0.83,0.97)$ & $0.91(0.84,0.98)$ \\
\hline & Index 2 & & \\
\hline Stomach cancer & Low & Medium & High \\
\hline Index 1 & & & \\
\hline Low & 1.00 & $0.97(0.88,1.07)$ & $0.81(0.75,0.88)$ \\
\hline Medium & $0.94(0.86,1.03)$ & $1.01(0.93,1.11)$ & $0.88(0.80,0.96)$ \\
\hline High & $0.84(0.77,0.92)$ & $0.88(0.81,0.96)$ & $0.83(0.76,0.90)$ \\
\hline & Index 2 & & \\
\hline ARIt & Low & Medium & High \\
\hline Index 1 & & & \\
\hline Low & 1.00 & $0.95(0.79,1.13)$ & $0.14(0.89,1.46)$ \\
\hline Medium & $0.87(0.73,1.04)$ & $0.88(0.74,1.04)$ & $0.99(0.82,1.19)$ \\
\hline High & $0.90(0.75,1.07)$ & $0.98(0.82,1.18)$ & $1.01(0.85,1.21)$ \\
\hline
\end{tabular}

${ }^{\star}$ Chronic obstructive pulmonary diseases, †ARI acute respiratory infections. reducing the level of deprivation (one or both indices) of each zone to the lowest tertile or quintile and computing the reduction in model-fitted expected number of deaths. We formed nine levels of deprivation by criss crossing tertiles of Index 1 and those of Index 2: (Index 1, Index 2) = (low, low), (low, middle), (low, high), (middle, low), (middle, middle), (middle, high), (high, low), (high, middle), (high, high). The model contained indicators of five year age groups for age adjustment and assessed the relative risk across the nine deprivation levels using the low/low group as reference. The gradient of the association can be assessed by comparing relative risk of death across tertiles of each deprivation index (that is, low, middle and high) for the same level of the other index. This approach permitted us to investigate potential effect modifications of one index by another. To account for within zone correlation of mortality risk, we used the Generalized Estimating Equation modification of Poisson regression. ${ }^{23}$

\section{Results}

Tables 2 and 3 show the crude associations of deprivation with cause specific mortality by quintiles of Index 1 and Index 2 separately. Positive associations are observed in both men and women for many of the top 10 causes of death with varying degrees of association. Tables 4 and 5 show the relative mortality risk (RMR) by tertiles of two deprivation indices for top leading causes of death in each gender respectively.

The associations between the deprivation indices and each cause of death are shown in figures 1 and 2 for men and women, respectively. Effects of Index 2 for the same level of Index 1 can be observed by looking at the slopes of the lines. Similarly, effects of Index 1 for the same level of Index 2 can be assessed by looking at specific symbols from left to right (that is, circles, crosses, and squares for low, middle, and high tertile of Index 2, respectively).

Figure 1 shows strong positive associations of the first six leading causes of death among men with the deprivation levels. Index 2 showed a strong association with ischaemic heart disease, lung cancer, chronic obstructive pulmonary diseases (COPD), and cirrhosis, while Index 1 showed a strong association with cerebrovascular disease and COPD. Percentages of excess mortality were $20 \%-30 \%$ for ischaemic and other heart diseases and $40 \%-$ $60 \%$ for cerebrovascular disease, lung cancer, COPD, and cirrhosis when comparing the most deprived (furthest right, squares) with the least deprived (furthest left, filled circles). Some interactions of two indices were observed: Index 1 had detrimental effects on ischaemic heart disease for zones with low Index 2 and on other heart disease for zones with low or middle Index 2 . Regarding the other four causes of death, no clear association was found except a negative association of traffic accidents with Index 2. Negative associations of Index 1 were observed with prostate 
Table 5 Relative mortality risk (and 95\% CI) by two indices of deprivation (Index 1, Index 2) and tertiles (low, medium, high) for top 10 leading causes of death among women

\begin{tabular}{|c|c|c|c|}
\hline \multirow[b]{2}{*}{ Cerebrovascular disease } & \multicolumn{3}{|l|}{ Index 2} \\
\hline & Low & Medium & High \\
\hline \multicolumn{4}{|l|}{ Index 1} \\
\hline Low & 1.00 & $1.12(1.03,1.22)$ & $1.08(0.92,1.27)$ \\
\hline Medium & $1.21(1.14,1.28)$ & $1.21(1.13,1.29)$ & $1.33(1.25,1.42)$ \\
\hline \multirow[t]{2}{*}{ High } & $1.56(1.48,1.65)$ & $1.60(1.52,1.69)$ & $1.56(1.47,1.65)$ \\
\hline & \multicolumn{3}{|l|}{ Index 2} \\
\hline All other heart diseases & Low & Medium & High \\
\hline \multicolumn{4}{|l|}{ Index 1} \\
\hline Low & 1.00 & $1.01(0.94,1.10)$ & $1.03(0.92,1.15)$ \\
\hline Medium & $1.08(1.00,1.17)$ & $1.03(0.93,1.14)$ & $1.08(0.98,1.20)$ \\
\hline \multirow[t]{2}{*}{ High } & $1.17(1.08,1.27)$ & $1.21(1.11,1.32)$ & $1.29(1.19,1.41)$ \\
\hline & \multicolumn{3}{|l|}{ Index 2} \\
\hline Ischaemic heart disease & Low & Medium & High \\
\hline \multicolumn{4}{|l|}{ Index 1} \\
\hline Low & 1.00 & $1.16(1.01,1.33)$ & $1.23(1.01,1.49)$ \\
\hline Medium & $1.10(0.96,1.26)$ & $1.23(1.07,1.42)$ & $1.34(1.17,1.54)$ \\
\hline \multirow[t]{2}{*}{ High } & $1.17(1.02,1.35)$ & $1.27(1.11,1.46)$ & $1.44(1.26,1.65)$ \\
\hline & \multicolumn{3}{|l|}{ Index 2} \\
\hline Diabetes & Low & Medium & $\mathrm{High}$ \\
\hline
\end{tabular}

\begin{tabular}{|c|c|c|c|}
\hline & & & \\
\hline \multicolumn{4}{|l|}{ Index 1} \\
\hline Low & 1.00 & $1.11(0.98,1.27)$ & $1.16(0.95,1.42)$ \\
\hline Medium & $1.16(1.04,1.29)$ & $1.22(1.09,1.37)$ & $1.50(1.33,1.69)$ \\
\hline \multirow[t]{2}{*}{ High } & $1.32(1.18,1.48)$ & $1.48(1.32,1.65)$ & $1.63(1.46,1.82)$ \\
\hline & Index 2 & & \\
\hline
\end{tabular}

\begin{tabular}{|c|c|c|c|}
\hline Atherosclerosis & Low & Medium & High \\
\hline \multicolumn{4}{|l|}{ Index 1} \\
\hline Low & 1.00 & $1.22(1.08,1.38)$ & $1.30(1.10,1.52)$ \\
\hline Medium & $1.32(1.15,1.50)$ & $1.53(1.29,1.83)$ & $1.38(1.20,1.60)$ \\
\hline \multirow[t]{2}{*}{ High } & $1.15(1.00,1.32)$ & $1.30(1.11,1.53)$ & $1.33(1.14,1.55)$ \\
\hline & \multicolumn{3}{|l|}{ Index 2} \\
\hline Breast cancer & Low & Medium & High \\
\hline \multicolumn{4}{|l|}{ Index 1} \\
\hline Low & 1.00 & $1.04(0.92,1.18)$ & $1.07(0.93,1.24)$ \\
\hline Medium & $0.98(0.86,1.12)$ & $0.99(0.87,1.13)$ & $1.01(0.89,1.15)$ \\
\hline \multirow[t]{2}{*}{ High } & $0.80(0.70,0.92)$ & $0.86(0.75,0.99)$ & $0.89(0.78,1.02)$ \\
\hline & \multicolumn{3}{|l|}{ Index 2} \\
\hline$C O P D$ & Low & Medium & High \\
\hline
\end{tabular}

\begin{tabular}{llll}
\cline { 2 - 3 } COPD & Low & Medium & High \\
\hline Index 1 & & & \\
$\quad$ Low & 1.00 & $1.15(1.06,1.25)$ & $1.01(0.79,1.29)$ \\
Medium & $1.15(1.05,1.27)$ & $1.30(1.18,1.43)$ & $1.27(1.17,1.39)$ \\
High & $1.35(1.23,1.49)$ & $1.33(1.21,1.46)$ & $1.24(1.13,1.37)$ \\
\hline & &
\end{tabular}

\begin{tabular}{llll} 
Dementia & Low & Medium & High \\
\hline Index 1 & 1.00 & $0.95(0.66,1.37)$ & $0.99(0.67,1.47)$ \\
$\quad$ Low & $0.97(0.68,1.39)$ & $1.05(0.73,1.52)$ & $1.10(0.76,1.60)$ \\
Medium & $0.71(0.50,1.03)$ & $0.78(0.54,1.14)$ & $0.56(0.38,0.82)$ \\
High & & &
\end{tabular}

\begin{tabular}{|c|c|c|c|}
\hline \multirow[b]{2}{*}{$A R I$} & \multicolumn{3}{|l|}{ Index 2} \\
\hline & Low & Medium & High \\
\hline \multicolumn{4}{|l|}{ Index 1} \\
\hline Low & 1.00 & $0.88(0.74,1.05)$ & $0.93(0.75,1.14)$ \\
\hline Medium & $0.88(0.74,1.05)$ & $0.82(0.69,0.98)$ & $0.85(0.70,1.04)$ \\
\hline \multirow[t]{2}{*}{ High } & $0.91(0.76,1.08)$ & $0.89(0.74,1.06)$ & $0.95(0.79,1.14)$ \\
\hline & \multicolumn{3}{|l|}{ Index 2} \\
\hline Colon cancer & Low & Medium & High \\
\hline \multicolumn{4}{|l|}{ Index 1} \\
\hline Low & 1.00 & $1.06(0.97,1.16)$ & $1.08(0.98,1.19)$ \\
\hline Medium & $1.00(0.91,1.09)$ & $0.99(0.91,1.08)$ & $1.06(0.98,1.15)$ \\
\hline High & $0.91(0.83,1.01)$ & $0.96(0.88,1.06)$ & $0.93(0.85,1.02)$ \\
\hline
\end{tabular}

Abbreviations as in table 4 .
KEY POINTS

- Health inequality is a widespread phenomenon in the majority of the leading causes of deaths of the nation.

- Increasing levels of deprivation indices are associated with mortality risk differently by both cause and gender.

- Deprivation effects manifest largely as unfavourable health behaviours related to the constraints of material conditions, leading to excess risk in gender specific sets of causes of deaths.

- Material deprivation determines health inequality through both an increase of general susceptibility to ill health and a set of specific factors/causes.

and stomach cancer for zones with middle/high and low/middle levels of Index 2, respectively.

Figure 2 shows strong positive associations for the first seven leading causes of death among women with deprivation levels except breast cancer: Index 1 showed a strong association with cerebrovascular disease, ischaemic and other heart diseases, diabetes, and COPD, while Index 2 showed a strong association with ischaemic heart disease, diabetes, and atherosclerosis. Percentages of excess mortality were $40 \%-60 \%$ for cerebrovascular disease, ischaemic heart disease, diabetes, and $20 \%-40 \%$ for other heart disease, atherosclerosis, and COPD when comparing the most deprived (furthest right, squares) with the least deprived (furthest left, filled circles). Index 2 had detrimental effects on other heart disease only for zones with high Index 1 . Breast and colon cancer showed weak negative associations with Index 1 but weak positive associations with Index 2 . Zones with high Index 1 appeared to have $20 \%-40 \%$ less dementia mortality.

\section{Discussion}

This paper investigated health inequalities in Spain using nationwide comprehensive mortality data aggregated for the period of 1987-1995 for 10 leading causes of death in each gender. We found strong detrimental associations of small area deprivation levels with gender specific sets of causes of death: the top six leading causes of death for men and the top seven leading causes of death for women, except breast cancer. The public health importance of this evidence is far reaching: these causes of death accounted for about half of the nation's total mortality burden $(46.9 \%$ for men and $50.4 \%$ for women) and the gradients of their associations were remarkably steep. Health inequality is not confined to some selected causes of death: rather it is a phenomenon associated with the leading causes of death of the nation.

In this study the steepest gradients were found mostly with respect to Index 2 for lung cancer, COPD, and cirrhosis among men and for heart disease and diabetes among women. These are smoking and alcohol related causes of death in men and diet related causes of death in women. Those findings are by and large 
consistent with results available from an individual-based multi-country study that showed differences in cause of death pattern in middle aged men and women by educational level. ${ }^{17}$ For example, inequalities in mortality attributable to lung cancer or respiratory diseases were consistently very large among men but small or even absent among women. Cigarette smoking, alcohol consumption and bad nutrition are socially approved individual ways to cope with, and temporarily escape, from adverse living conditions. For instance, people smoke to reduce anxiety, fear, and distress. ${ }^{24}$ These unhealthy behaviours, however, have to

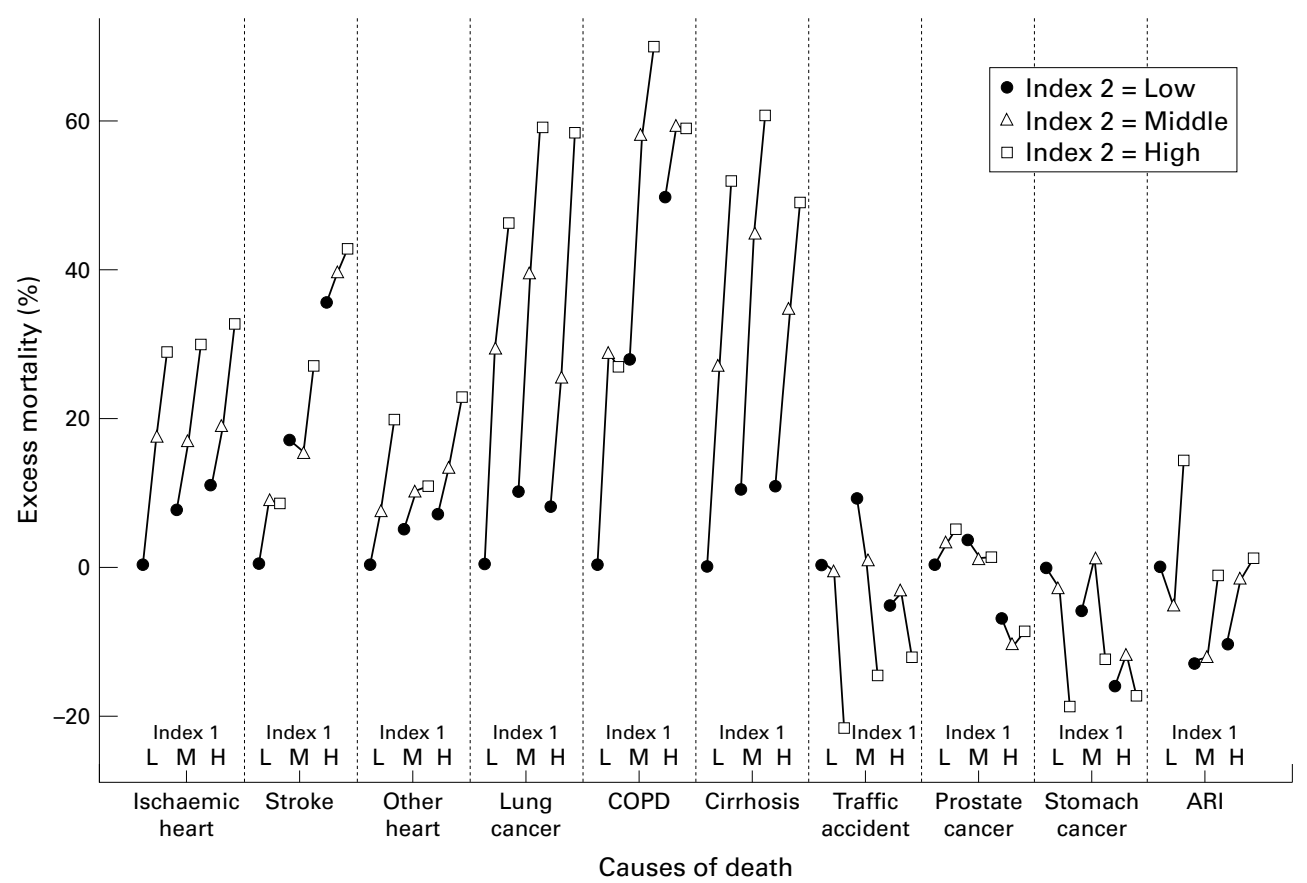

Figure 1 Excess mortality by two indices of deprivation for each of the top 10 leading causes of death among men. Nine levels of deprivation were formed by criss crossing tertiles of Index 1 and tertiles of Index 2. Low, middle, and high tertiles of Index 2 are shown by symbols filled circles, crosses, and squares, respectively, and connected by a line within each tertile of Index 1. Tertiles of Index 1 are arranged from left to right in the order of low, middle, and high tertiles. To assess Index 1 effects within each tertile of Index 2, observe the same symbol from left to right. To assess Index 2 effects within each tertile of Index 1, observe the slope of each line.

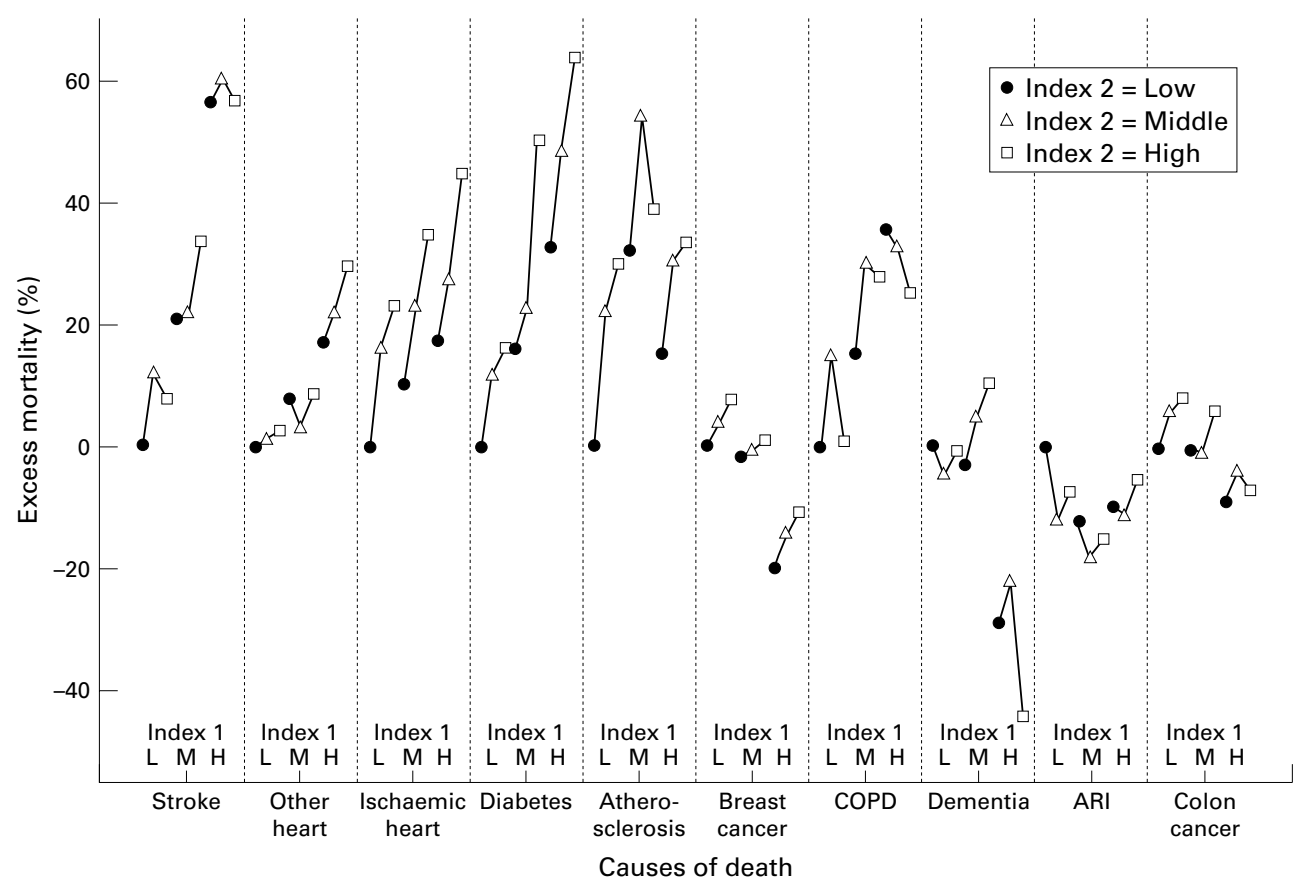

Figure 2 Excess mortality by two indices of deprivation for each of the top 10 leading causes of death among women. Nine levels of deprivation were formed by criss crossing tertiles of Index 1 and tertiles of Index 2 . Low, middle, and high tertiles of Index 2 are shown by symbols filled circles, crosses, and squares, respectively, and connected by a line within each tertile of Index 1. Tertiles of Index 1 are arranged from left to right in the order of low, middle, and high tertiles. To assess Index 1 effects within each tertile of Index 2, observe the same symbol from left to right. To assess Index 2 effects within each tertile of Index 1, observe the slope of each line. 
be understood in the context of the constraints of material conditions. ${ }^{25}$ Area level deprivation, specifically, the type of deprivation represented by Index 2, may influence individual conduct directly through psychosocial mechanisms determining convictions and attitudes as well as limiting opportunities and resources for changing behaviour. ${ }^{1426}$ Caution must be exercised, however, in the interpretation of specific types of deprivation, represented by Indices 1 and 2, in association with the observed cause-genderspecific mortality inequalities. While Index 1 captured a deprivation dimension measured by unemployment, illiteracy and low social class and Index 2 represented a deprivation dimension measured by overcrowding with a small component of unemployment and illiteracy, these indices were based on our Spanish data and may not be generalisable to the same variables in other countries. Although we did not perform formal statistical inference to test possible interaction effects between the two deprivation indices, interactions may be assessed in both figures and in tables 4 and 5. From those assessments, however, such interactions seemed relatively rare.

Studies have found that both individual and area-based socioeconomic measures may make independent contributions on mortality, suggesting the need to study health inequality by using both of these measures. ${ }^{1027}$ We analysed the associations between area-based deprivation and cause specific mortality but other factors such as individual behaviours and psychobiological factors that lead to death were not investigated. To elucidate complex links of those individual-based and area-based factors with cause specific mortality risk is a challenge for future research. Findings of this study are consistent with the two hypotheses suggested by Marmot and colleagues to explain social inequalities in mortality ${ }^{28}$ : material deprivation determines health inequality through both (1) an increase of general susceptibility to ill health, leading to excess mortality in a wide range of causes, and (2) a set of specific factors, resulting in increased risk of death from a specific set of causes in each gender.

Individual-based research of middle aged men has shown that the mortality disadvantage of low social classes is similar in size across countries, but different in the specific causes of death involved. ${ }^{16}{ }^{29}$ For example, in France the steepest social class gradient was observed in alcohol related causes of death while in Finland accidents and cardiovascular diseases were the principal causes of death leading to inequalities. $^{30}$ Cardiovascular disease mortality inequalities were larger in the Nordic countries and England and Wales than in the south of Europe. ${ }^{31}$ Southern European countries share common characteristics and risk factors that are likely to explain their differential socioeconomic-mortality patterns as compared with central and northern countries. ${ }^{31}{ }^{32}$ Cause specific mortality research across countries may provide important clues to understand social determinants that lead to different causes of death. There has been no multicountry comparative study assessing differential effects of area-based deprivation on cause specific mortality. This nationwide study in a southern European country contributes a piece of evidence that should be complemented by similar studies in other countries.

Policy interventions to reduce health inequalities should consider causes of death and their different degrees and patterns of associations with deprivation indices in two complementary ways. The first one is based on the notion that material deprivation manifests through various social, cultural, and economic determinants leading to various deprivation related causes of death. ${ }^{12}{ }^{25}$ Interventions to reduce inequalities by improvements of material resources may reduce overall mortality differentials across a number of pathways that lead to specific causes of death. Health policy makers should keep in mind that an intervention at the general level, with a modest impact on many diseases, may be far more relevant than one that has a relatively strong impact on one or few diseases. ${ }^{33}$ Secondly, an understanding of those cause specific associations may suggest specific strategies for prevention and allow effective targeting of areas at higher risk for specific causes. ${ }^{34}$ For example, we observed, that in both genders cerebrovascular disease and COPD were strongly associated with Index 1. Prevention strategies for cerebrovascular disease and COPD can be sought by considering potential risk factors that might correlate with Index 1 levels and by focusing on the areas with high Index 1 . Policies aimed at reducing socioeconomic differentials in health should pay as much attention to the characteristics of deprived areas in which people live as to the characteristics of the people who live in those areas.

Funding: this study was partially funded by a grant from the Fondo de Investigaciones Sanitarias (FIS 99/1225).

Conflicts of interest: none.

1 Townsend P, Phillimore P, Beattie A. Health and deprivation. Inequality and the north. London: Croom Helm, 1988.

2 Carstairs V, Morris R. Deprivation: explaining differences in mortality between Scotland and England and Wales. BMF 1989;299:886-9.

3 Phillimore P, Beattie A, Townsend P. Widening inequality of health in northern England, 1981-91. BMF 1994;308: 1125-8.

4 McLoone P, Boddy FA. Deprivation and mortality in Scotland, 1981 and 1991. BMf 1994;309:1465-70.

5 McCarron PG, Davey Smith G, Womersley JJ. Deprivation and mortality in Glasglow from 1980 to 1992 . BMF 1994; 309:1481-2.

6 Kunst AE, Looman CW, Mackenbach JP. Socio-economic mortality differences in The Netherlands in 1950-1984: a mortality differences in The Netherlands in 1950-1984: a
regional study of cause-specific mortality. Soc Sci Med. regional study of

7 Sundquist J, Bajekal M, Johansson SE. The UPA (underprivileged area) score and mortality in Swedish municipalities. Scand F Prim Health Care 1997;15:203-9.

8 Benach J, Borrell C, García MD, et al. Desigualdades sociales en mortalidad en áreas pequeñas en España. Sociedad Española de Salud Pública y Administración Sanitaria. Informe SESPAS: La salud pública y el futuro del estado de bienestar. Granada: Sespas, 1998:141-75.

9 Benach J, Yasui Y. Geographical patterns of excess mortality in Spain explained by two indices of deprivation. $\mathcal{F}$ Epidemiol Community Health 1999;53:423-31.

10 Davey Smith G, Hart C, Hole D, et al. Education and occupational social class: which is the more important indicator of mortality risk?. F Epidemiol Community Health. 1998;52: 153-60.

11 Carstairs V, Morris R. Deprivation and health in Scotland. Aberdeen: Aberdeen University Press, 1991.

12 Marmot M, Bobak M, Davey-Smith G. Explanations for social inequalities in health. In: Amick III BC, Levine S, 
Tarlov AR, et al, eds. Society and health. New York: Oxford University Press, 1995.

13 Mackenbach JP, Kunst AE, Looman CWN. Cultural and economic determinants of geographical mortality patterns in the Netherlands. F Epidemiol Community Health 1991;45: 231-37.

14 Eames M, Ben-Shlomo Y, Marmot MG. Social deprivation and premature mortality: regional comparison across England. BMF 1993;307:1097-102.

15 Law MR. Morris JK. Why is mortality higher in poorer areas and in more northern areas of England and Wales? 7 Epidemiol Community Health 1998;52:344-52.

16 Kunst AE, Groenhof F, Mackenbach JP. The EU Working Group on Socioeconomic Inequalities in Health. Occupational class and cause specific mortality in middle aged men in 11 European countries: comparison of population based studies. BMF 1998;316:1636-42.

17 Mackenbach JP, Kunst AE, Groenhof F, et al. Socioeconomic inequalities in mortality among women and among men: an international study. Am f Public Health 1999;89: men: an

18 Navarro V, Benach J and the Scientific Comission for the study of Spanish health inequalities. Desigualdades sociales en salud en España. Madrid: Spanish Ministry of Health, 1996.

19 Benach J, García MD, Donado-Campos J. GIS for mapping mortality inequalities in Spain and its socioeconomic determinants. Constructing regions using small areas. International Symposium on Computer Mapping in Epidemiol ogy and Environmental Health. 1995. Tampa, FL: Book of Proceedings, 1997:314-22.

20 Martínez MV, Llácer A. Mortalidad en Espana 1995. Mortalidad general y principales causas de muerte y de años potenciales de vida perdidos. Boletín Epidemiológico Semanal 1998;6:105-16.

21 Benavides FG, Segura A, Godoy C. Estadísticas de mortalidad en España: pequeños problemas, grandes perspectivas. Revisiones de Salud Pública 1991;2:43-66.

22 Clayton D, Hills M. Statistical models in epidemiology. Oxford: Oxford University Press, 1993.
23 Liang KY, Zeger SL. Longitudinal data analysis using Generalized Linear Models. Biometrika 1986;73:13-22.

24 Benfari R, Ockene J, McIntyre K. Control of cigarette smoking from a psychological perspective. Annu Rev Public Health 1982;3:101-28.

25 Shaw M, Dorling D, Davey Smith G. Poverty, social exclusion, and minorities. In: Marmot M, Wilkinson RG, eds. Social determinants of health. Oxford: Oxford University Press, 1999.

26 Haan M, Kaplan GA, Camacho T. Poverty and health. Prospective evidence from the Alameda County study. $A m \mathcal{F}$ Epidemiol 1987;125:989-98.

27 Langford IH, Bentham G. Regional variations in mortality rates in England and Wales: an analysis using multilevel modelling. Soc Sci Med 1996;42:897-908.

28 Marmot M, Bobak M, Davey Smith D. Explanations for Social inequalities in health. In: Amick III BC, Levine S, Tarlov AR, et al, eds. Society and health. New York: Oxford University Press, 1995:172-210.

29 Kunst AE, Groenhof F, Andersen O, et al. Occupational class and ischemic heart disease mortality in the United States and 11 European countries. Am $\mathcal{F}$ Public Health 1999;89:47-53.

30 Leclerc A, Lert F, Fabien C. Differential mortality: some comparisons between England and Wales, Finland and France, based on inequalities measures. Int 7 Epidemiol 1990;19:1001-10.

31 Cavelaars A. Cross-national comparisons of socio-economic differences in health indicators. [Thesis]. Rotterdam: Erasmus University, 1998.

32 Borrell C, Pasarin MI. The study of social inequalities in health in Spain: where are we? f Epidemiol Community Health 1999;53:388-9.

33 Link BG, Phelan J. Social conditions as fundamental causes of disease. F Health Soc Behav 1995; Spec no:80-94.

34 Carstairs V. Deprivation indices: their interpretation and use in relation to health. 7 Epidemiol Community Health 1995;49 (suppl 2):S3-8. 